\title{
TOXICITY OF SEA GRASS EXTRACT (Eucheuma cottonii AND Gracillaria sp) TO LARVA Artemia salina
}

\author{
Danil Rama Putra ${ }^{1}$, Aras Mulyadi ${ }^{1}$, Zulkifli $^{1}$ \\ ${ }^{1}$ Department of Marine Science, Faculty of Fisheries and Marine Universitas Riau, Pekanbaru \\ *danielrama707@gmail.com
}

\begin{abstract}
Seaweed is a source of foreign exchange, namely as the main export product and a source of income for coastal communities. Previous research on species Eucheuma cottonii and Gracillaria sp contain bioactive compounds that can be used in medicine, for example as anti-cancer. The purpose of this study was to determine the $\mathrm{LC}_{50}$ value and safe concentration of Artemia salina larvae. The research was conducted at the Chemical Oceanography Laboratory of the Department of Marine Sciences, Faculty of Fisheries and Marine, Riau University in July 2020. The method used in this research is the experimental method. The results of the research on the toxicity of the n-hexane extract of seaweed E. cottonii and Gracillaria sp had bioactivity compounds against $A$. salina shrimp larvae, indicated by a small $\mathrm{LC}_{50}$ value $(<1000 \mathrm{ppm})$, namely $62.62 \mathrm{ppm}$ for $E$. cottonii and 83.55. ppm for Gracillaria sp, so it is included in the toxic category. According to research by experts, if the extract or compound tested is less than $1000 \mathrm{ppm}$, it is considered that there is biological activity. For a safe concentration for the survival of A. salina, $6.262 \mathrm{ppm}$ for E. cottonii and 8.355 ppm for Gracillaria sp.
\end{abstract}

Keywords: Toksisitas, Eucheuma cottonii, Gracillaria sp, Artemia salina, n-heksana

\section{PENDAHULUAN}

Rumput laut merupakan salah satu sumber devisa negara, yaitu sebagai produk ekspor utama dan sumber pendapatan bagi masyarakat pesisir. Pemanfaatan rumput laut saat ini beragam dan mencakup ke dalam bidang pangan, industri, serta farmasi. Rumput laut diketahui memiliki senyawa bioaktif beragam yang masingmasing spesies memiliki keunikannya tersendiri. Rumput laut sudah sering digunakan untuk pengobatan oleh masyarakat pesisir, antara lain sebagai obat batuk, radang dan cacingan. Kegunaan rumput laut yang beragam tersebut ternyata pada tiap kelasnya terdapat senyawa yang berbeda dan memiliki sifat kimia dan fisika yang spesifik pula.
Rumput laut Eucheuma cottonii dan Gracillaria sp merupakan alga multiseluler yang diduga memiliki senyawa-senyawa hasil metabolisme sekunder berupa alkaloid atau flavonoid. Senyawa-senyawa tersebut kemungkinan merupakan senyawa bioaktif yang dapat digunakan dalam dunia pengobatan, misalnya sebagai antikanker [1].

Uji Toksisitas merupakan metode uji yang digunakan untuk mengetahui tingkat toksik dari suatu senyawa yang ditentukan dalam waktu singkat setelah pemberian suatu sediaan. Uji toksisitas dengan metode BSLT ini memiliki spektrum aktifitas farmakologi yang luas, prosedurnya sederhana, cepat dan tidak membutuhkan biaya yang besar, serta hasilnya dapat dipercaya. Selain itu, metode ini sering 
dikaitkan sebagai acuan atau landasan dalam pengujian antikanker. Dengan alasan-alasan tersebut, maka uji ini sangat tepat digunakan dalam penelitian bahan alam [2].

Penelitian ini menerapkan metode Brine Shrimp Lethality Test (BSLT) dengan menggunakan larva udang $A$. salina Leach sebagai hewan uji. Metode ini merupakan salah satu metode yang banyak digunakan untuk pencarian senyawa antikanker baru yang berasal dari tanaman. Hasil uji toksisitas dengan metode ini telah terbukti memiliki korelasi dengan daya sitotoksis senyawa antikanker [3].

Pelarut yang digunakan pada penelitian ini adalah n-heksana karena memiliki titik didih yang rendah dan mudah diuapkan tanpa menggunakan suhu yang tinggi, bersifat inert, serta dapat melepaskan komponen nonpolar dari suatu jaringan tumbuhan untuk mendapatkan senyawa aktif yang terkandung dalam rumput laut. Dalam penelitian ini, informasi mengenai seberapa besar nilai $\mathrm{LC}_{50}$ berdasarkan uji toksisitas belum terdokumentasikan dengan baik, begitu juga dengan konsentrasi yang aman (safe concentration) dari ekstrak n-heksana rumput laut E. cottonii dan Gracillaria sp terhadap larva $A$. salina juga belum banyak diteliti. Apakah aman atau tidak tentu perlu diketahui dengan baik.

Adapun tujuan penelitian ini adalah untuk mengetahui nilai $\mathrm{LC}_{50}$ ekstrak nheksana rumput laut E. cottonii dan Gracillaria sp berdasarkan uji toksisitas terhadap larva udang A. salina Leach dan untuk mengetahui konsentrasi yang aman (safe concentration) ekstrak n-heksana rumput laut E. cottonii dan Gracillaria sp terhadap larva udang $A$. salina Leach.

\section{METODE PENELITIAN Waktu dan Tempat}

Penelitian ini dilaksanakan pada bulan Juli 2020. Pengambilan sampel rumput laut dilakukan di Desa Sugie
Kabupaten Karimun Provinsi Kepulauan Riau. Sedangkan kegiatan ekstraksi rumput laut dilakukan di Laboratorium Kimia Organik FMIPA. Untuk Uji toksisitas dilakukan pada Laboratorium Oseanografi Kimia Jurusan Ilmu Kelautan Fakultas Perikanan dan Kelautan, Universitas Riau.

\section{Metode Penelitian}

Penelitian ini dilakukan dengan menggunakan metode eksperimen. Sampel rumput laut diekstraksi secara maserasi menggunakan pelarut n-heksana. Ekstrak yang diperoleh dipekatkan dengan rotary vacuum evaporator pada suhu $40-50^{\circ} \mathrm{C}$, hingga diperoleh ekstrak pekat n-heksana, yang selanjutnya diuji toksisitasnya dengan menggunakan larva udang $A$. salina. Proses pengujian ini untuk mengetahui tingkat toksisitas dan konsentrasi yang aman masing-masing ekstrak rumput laut dengan pelarut $\mathrm{n}$-heksana terhadap larva udang $A$. salina melalui nilai $\mathrm{LC}_{50}$.

\section{Prosedur Penelitian \\ Penanganan Sampel Rumput Laut}

Sampel rumput laut dengan berat masing-masing $2 \mathrm{~kg}$ berat basah dicuci bersih dengan air laut yang bersih guna menghilangkan sisa lumut yang menempel pada rumput laut tersebut, kemudian sampel dimasukkan ke dalam kantong plastik dan disimpan dalam ice box yang telah diberi es batu sebelumnya guna mempertahankan kesegaran rumput laut sebelum dilakukan penanganan selanjutnya.

\section{Ekstraksi Rumput Laut}

Proses pemisahan komponen bioaktif dilakukan dengan cara ekstraksi dengan cara sampel rumput laut yang sudah dibersihkan ditimbang beratnya selanjutnya dipotong kecil-kecil dan direndam dalam botol sampel, ekstraksi menggunakan metode maserasi dengan pelarut $n$-heksana. Rumput laut dimaserasi menggunakan pelarut n-heksana selama $3 \times 24$ jam dengan sesekali pengadukan. Selanjutnya 
rendaman disaring dengan kertas saring dan corong, ampas dipisahkan dari maserat, kemudian maserat tersebut diuapkan dengan rotary evaporator hingga diperoleh ekstrak kental n-heksana rumput laut sebanyak 2 kali pengulangan, ekstrak kental yang diperoleh dari maserasi pertama hingga kedua digabung kedalam botol sampel dan siap untuk dijadikan bahan uji.

\section{Penetasan Kista Artemia sp.}

Sebelum melakukan penetasan kista artemia dilakukan persiapan alat-alat dan bahan yang dibutuhkan seperti wadah berbentuk kerucut yang transparan, aquades, gunting, selang aerasi, batu aerasi lalu dilakukan pengukuran salinitas air laut menggunakan handrefractometer dengan nilai 33\%o. Hasil ini sesuai dengan penelitian Gusrina dalam [4] yang menyatakan bahwa kista $A$. salina dapat ditetaskan pada media yang mempunyai salinitas 5-35\%o. Selanjutnya dilakukan penetasan kista artemia, telur A. salina dicuci terlebih dahulu, yakni ditaburkan dan direndam dalam wadah berisi aquades selama satu jam.

Penetasan kista Artemia sp dilakukan dengan menyiapkan air laut buatan $1 \mathrm{~L}$ dengan salinitas berkisar antara 33-35\%o dan telah diukur $\mathrm{pH}$ (8-9), serta diberi penerangan dengan cahaya lampu 40 watt untuk menghangatkan suhu dalam penetasan agar suhu penetasan $25-31^{\circ} \mathrm{C}$ tetap terjaga dan merangsang proses penetasan dengan menggunakan aerator, selanjutnya dimasukkan kista tersebut yang telah ditimbang sebanyak dua gram ke dalam air laut yang telah dimasukkan ke dalam wadah, pencampuran harus dilakukan dengan hati-hati agar kista artemia tidak rusak. Selanjutnya aerator dan perangkatnya di "on" dengan kekuatan yang maksimal untuk memaksimalkan oksigen terlarut. Telur A. salina Leach dibiarkan selama 36-48 jam sampai menetas menjadi nauplius yang matang dan siap digunakan dalam percobaan. Telur akan menetas dalam waktu 18 - 48 jam dan akan bergerak secara alamiah menuju daerah terang sehingga larva udang terpisah dari kulit telur. Larva yang sehat bersifat fototropik dan siap dijadikan hewan uji pada umur 36-48 jam. Larva dipisahkan dari telurnya dengan pipet ke dalam vial yang berisi air laut buatan [5].

\section{Uji Toksisitas}

Setelah larva A. salina menetas dalam waktu $18-24$ jam, dilakukan proses aklimatisasi selama 24 jam di laboratorium untuk menyesuaikan kondisi lingkungan asal hewan uji dengan kondisi laboratorium sebelum digunakan dalam uji toksisitas.

Uji pendahuluan dilakukan untuk mengetahui nilai ambang atas (N) dan ambang bawah (n) dari penggunaan konsentrasi untuk uji toksisitas. Variasi konsentrasi ekstrak diperoleh dengan terlebih dahulu di buat larutan stok ekstrak $10000 \mathrm{ppm}$. Larutan uji di buat dari larutan stok $10000 \mathrm{ppm}$ dengan cara dipipet $1 \mu \mathrm{L}$, $10 \mu \mathrm{L}, 100 \mu \mathrm{L}$, dan $1000 \mu \mathrm{L}$ ke dalam labu ukur $10 \mathrm{ml}$, selanjutnya diuapkan sampai kering selama 24 jam agar kematian larva tidak dipengaruhi oleh pelarutnya.

Setelah pelarutnya mengering, dimasukkan $100 \mu \mathrm{L}$ dimetil sulfoksida, 2 $\mathrm{ml}$ air laut, dan setetes larutan ragi roti kemudian dikocok sampai ekstrak dapat larut dalam air laut. Kemudian ditambahkan air laut sampai volumenya menjadi $10 \mathrm{ml}$ dan dikocok kembali sampai larutan menjadi homogen. Sehingga konsentrasi masing-masing larutan menjadi 1 ppm, 10 ppm, 100 ppm, dan 1000 ppm. Selanjutnya larutan dengan masing-masing konsentrasi dipindahkan ke dalam tabung reaksi, kemudian dimasukkan 10 ekor larva udang yang sehat ke dalam tabung reaksi yang sudah berisi larutan ekstrak. Pengamatan terhadap kematian hewan uji dilakukan pada $6,12,18$, dan 24 jam dan di amati mortalitasnya dengan menghitung jumlah A. salina yang mati. Hasil uji 
dikatakan efektif terhadap A. salina apabila ekstrak yang diujikan menyebabkan 50\% kematian pada konsentrasi < 1000 ppm. Menurut [6] uji pendahuluan dilakukan sebanyak 2 (dua) kali untuk menetapkan konsentrasi yang menyebabkan 50\% kematian hewan uji.

Uji persistensi. Bertujuan untuk melihat penurunan daya racun bahan uji terhadap waktu uji. Pada tiap konsentrasi 1 ppm, 10 ppm, 100 ppm, dan 1000 ppm, dimasukkan 10 ekor larva artemia ke dalam wadah uji. Pengamatan terhadap kematian hewan uji dilakukan pada $6,12,18$, dan 24 jam [7]. Untuk melihat kapan media uji diganti dibuat grafik tingkat kematian dalam persen terhadap waktu saat pemasukaan hewan uji. Dari grafik tersebut dapat dilihat kecendrungan toksisitas itu menaik, menurun atau mendatar yang menunjukkan persistensinya [8] (Nedi et al., 2006).

Uji Toksisitas. Pada uji toksisitas, masing-masing media uji diisi dengan konsentrasi bahan uji sesuai hasil yang diperoleh dari perhitungan nilai ambang atas dan ambang bawah dengan variasi konsentrasi 1 ppm, 10 ppm, 100 ppm, dan 1000 ppm. Perlakuan uji toksisitas dilakukan dengan 3 kali pengulangan untuk mendapatkan data yang akurat. Variasi konsentrasi ekstrak diperoleh dengan terlebih dahulu di buat larutan stok ekstrak 10000 ppm dengan cara dimasukkan 100 mg ekstrak pekat ke dalam labu ukur $10 \mathrm{ml}$ dan dilarutkan dengan pelarutnya sampai tanda batas. Selanjutnya larutan yang diperoleh di pipet masing-masing sebanyak $1 \mu \mathrm{L}, 10 \mu \mathrm{L}, 100 \mu \mathrm{L}$, dan $1000 \mu \mathrm{L}$ ke dalam labu ukur $10 \mathrm{ml}$ dan pelarutnya diuapkan selama 24 jam.

Setelah pelarutnya mengering, dimasukkan $100 \mu \mathrm{L}$ dimetil sulfoksida, 2 $\mathrm{ml}$ air laut, dan setetes larutan ragi roti kemudian dikocok sampai ekstrak dapat larut dalam air laut. Selanjutnya ditambahkan air laut sampai volumenya menjadi $10 \mathrm{ml}$ dan dikocok kembali sampai larutan menjadi homogen. Sehingga konsentrasi masing-masing larutan menjadi 1 ppm, 10 ppm, 100 ppm, dan 1000 ppm. Lalu larutan dengan masing-masing konsentrasi dipindahkan ke dalam tabung reaksi, kemudian dimasukkan 10 ekor larva udang yang sehat ke dalam tabung reaksi yang sudah berisi larutan ekstrak.

Larutan kontrol dibuat dengan cara yang sama kecuali penambahan ekstrak, yaitu dengan cara dimasukkan $100 \mu \mathrm{L}$ dimetif sulfoksida, $2 \mathrm{ml}$ air laut, dan setetes larutan ragi roti ke dalam labu ukur $10 \mathrm{ml}$, kemudian dikocok sampai dapat larut dalam air laut. Lalu ditambahkan air laut sampai volumenya $10 \mathrm{ml}$ dan dikocok kembali hingga larutan menjadi homogen. Selanjutnya dipindahkan ke dalam tabung reaksi, Setelah itu, dimasukkan 10 ekor larva udang yang sehat ke dalam tabung reaksi yang telah berisi larutan kontrol. Terakhir, semua tabung reaksi diletakkan di bawah lampu neon 18 watt selama 24 jam dan di hitung jumlah larva A. salina yang mati (tidak bergerak aktif).

\section{Analisis Data}

Data yang diperoleh pada penelitian ini akan disajikan dalam bentuk tabel dan dijelaskan secara deskriptif mengacu pada sumber-sumber yang telah ada. Efek toksisitas dianalisis dari pengamatan dengan persen kematian:

$$
\% \text { Larva }=\frac{\text { Jumlah larva yang mati }}{\text { Jumlah larva uji }} \times 100 \%
$$

Dari persamaan tersebut kemudian dihitung $\mathrm{LC}_{50}$ dengan memasukkan nilai probit (50\% kematian). Suatu zat dikatakan toksik bila nilai $\mathrm{LC}_{50}<1000 \mathrm{ppm}$. Apabila pada kontrol ada larva yang mati maka \% persen kematian ditentukan dengan rumus abbot [9]:

$$
\% \text { kematian larva }=\frac{T-K}{10} \times 100 \%
$$

Keterangan :

$\mathrm{T}=$ Jumlah larva uji yang mati

$\mathrm{K}=$ Jumlah larva kontrol yang mati

$10=$ Jumlah larva uji 
Parameter yang digunakan adalah kematian A. salina melebihi $50 \%$ dari total larva uji. Efek toksisitas terhadap A. salina Leach ditentukan berdasarkan analis probit melalui tabel probit dan dibuat persamaan regresi linier.

Keterangan:

$$
\mathrm{Y}=\mathrm{aX}+\mathrm{b}
$$

$$
\begin{aligned}
\mathrm{y} & =\text { Log konsentrasi } \\
\mathrm{x} & =\text { Angka probit } \\
\mathrm{a} & =\text { Intersep } \\
\mathrm{b} & =\text { Slop }
\end{aligned}
$$

Persamaan tersebut dapat digunakan untuk mengetahui nilai $\mathrm{LC}_{50} 24$ jam dengan memasukkan nilai probit 5 (50\% kematian) ke persamaan tersebut sehingga diperoleh konsentrasi yang menyebabkan 50\% kematian.

Hasil nilai $\mathrm{LC}_{50}$ yang diperoleh dari analisis regresi dari masing - masing ekstrak rumput laut kemudian dicari konsentrasi aman (safe concentration) untuk mengetahui pada kisaran berapa A.salina bisa bertahan hidup dengan menggunakan faktor aplikasi menurut Wibisono dalam [8] yakni $10 \%$ dari nilai $\mathrm{LC}_{50}$.

\section{HASIL DAN PEMBAHASAN Ekstraksi Sampel}

\begin{tabular}{|c|c|c|c|c|c|}
\hline Sampel & $\begin{array}{c}\text { Berat Sampel } \\
(\mathrm{kg})\end{array}$ & Pelarut & $\begin{array}{c}\text { Volume } \\
\text { Pelarut }(\mathrm{ml}) \\
\end{array}$ & $\begin{array}{c}\text { Berat } \\
\text { Ekstrak (g) }\end{array}$ & $\begin{array}{c}\text { Warna } \\
\text { Ekstrak Pekat } \\
\end{array}$ \\
\hline E. cottonii & 2 & \multirow{2}{*}{ N-heksana } & 1000 & 2,365 & Hijau Pekat \\
\hline Gracillaria $\mathrm{sp}$ & 2 & & 1000 & 2,146 & Merah Pekat \\
\hline
\end{tabular}

Hasil maserasi rumput laut E. cottonii dan Gracillaria sp ditunjukkan pada Tabel 1.

Tabel 1. Hasil Ekstraksi Sampel

Ekstrak yang diperoleh dari ekstraksi menggunakan metode maserasi rumput laut jenis E. cottonii dan Gracillaria sp. dengan berat sampel masing-masing $2 \mathrm{~kg}$ menggunakan pelarut $n$-heksana didapatkan berat ekstrak pekat sebanyak 2,365 gram E. cottonii dengan warna ekstrak hijau pekat dan 2,146 gram Gracillaria sp dengan warna ekstrak merah pekat.

Prinsip dari metode maserasi adalah waktu kontak yang cukup lama antara pelarut dengan sampel yang diekstraksi, metode ini dipilih karena merupakan metode yang paling sederhana dengan peralatan yang relatif mudah untuk didapatkan

Menurut [10], pada proses maserasi pelarut akan masuk ke dalam sel melewati dinding sel. Isi sel akan larut, karena adanya perbedaan konsentrasi antara larutan di dalam dan luar sel. Larutan yang konsentrasi nya tinggi akan terdesak keluar dan diganti oleh cairan penyari dengan konsentrasi rendah (proses difusi).
Peristiwa tesebut berulang sampai terjadi keseimbangan konsentrasi antara larutan di luar sel dan di dalam sel.

\section{Kualitas Air}

Parameter kualitas air yang diukur selama penelitian, adalah suhu, $\mathrm{pH}$, salinitas dan oksigen terlarut. Kualitas air bagi perikanan didefinisikan sebagai kualitas air yang sesuai untuk mendukung kehidupan dan pertumbuhan larva A. salina yang dipengaruhi oleh parameter suhu, oksigen terlarut, $\mathrm{pH}$, dan salinitas [4]. Parameter kualitas air yang diukur selama penelitian masih mendukung kehidupan larva A. salina (Tabel 2). Pada penelitian ini kelangsungan hidup sangat dipengaruhi oleh kualitas air. Salah satu cara menciptakan lingkungan yang ideal adalah dengan melakukan penggantian air. Selama penelitian ini berlangsung, penyiponan, penggantian air dan pemberian aerasi pada media uji selalu dilakukan dan dikontrol, sehingga kualitas air dalam media uji 
dengan perlakuan maupun kontrol bisa dikatakan baik

Tabel 2. Pengukuran Kualitas Air

\begin{tabular}{clccc}
\hline No & Parameter & Hasil Pengukuran & Satuan & Baku Mutu * \\
\hline 1 & Suhu & 29 & ${ }^{\circ} \mathrm{C}$ & $26-32$ \\
2 & Salinitas & 30 & $\mathrm{ppt}$ & $28-34$ \\
3 & DO & 5,5 & $\mathrm{mg} / \mathrm{L}$ & $5,3-6,5$ \\
4 & pH & 7,8 & - & $7,1-8,2$ \\
\hline
\end{tabular}

*Sumber : (Kaharudin, 2018)

Pengaruh Penambahan Ekstrak Rumput Laut E. cottonii dan Gracillaria sp terhadap A. salina

Skrining toksisitas ekstrak rumput laut E. cottonii dan Gracillaria sp. dengan metode BSLT (Brine Shrimp Lethality
Test) menggunakan larva A. salina Leach berumur 48 jam, dengan konsentrasi 1, 10, 100, 1000 ppm.

Persentase tingkat mortalitas pada uji toksisitas ekstrak rumput laut E. cottonii disajikan pada Tabel 3.

Tabel 3. Hasil Uji Toksisitas Ekstrak Rumput Laut E. cottonii

\begin{tabular}{|c|c|c|c|c|c|c|c|c|}
\hline No & $\begin{array}{c}\text { Konsentrasi } \\
\text { (ppm) }\end{array}$ & $\begin{array}{c}\text { Log } 10 \\
\text { Konsentrasi }\end{array}$ & Ulangan & $\begin{array}{c}\text { Total } \\
\text { Larva (ind) } \\
\end{array}$ & $\begin{array}{l}\text { Larva Mati } \\
\text { (ind) }\end{array}$ & $\begin{array}{l}\text { Mortalitas } \\
\text { (ind) }\end{array}$ & $\begin{array}{c}(\%) \\
\text { Kematian }\end{array}$ & Probit \\
\hline \multirow{3}{*}{1} & \multirow{3}{*}{0 (kontrol) } & \multirow{3}{*}{ - } & 1 & 10 & 0 & \multirow{3}{*}{0} & \multirow{3}{*}{ - } & \multirow{3}{*}{-} \\
\hline & & & 2 & 10 & 0 & & & \\
\hline & & & 3 & 10 & 0 & & & \\
\hline \multirow{3}{*}{2} & \multirow{3}{*}{1} & \multirow{3}{*}{0} & 1 & 10 & 2 & \multirow{3}{*}{2} & \multirow{3}{*}{20} & \multirow{3}{*}{4,16} \\
\hline & & & 2 & 10 & 3 & & & \\
\hline & & & 3 & 10 & 1 & & & \\
\hline \multirow{3}{*}{3} & \multirow{3}{*}{10} & \multirow{3}{*}{1} & 1 & 10 & 3 & \multirow{3}{*}{4} & \multirow{3}{*}{40} & \multirow{3}{*}{4,75} \\
\hline & & & 2 & 10 & 5 & & & \\
\hline & & & 3 & 10 & 4 & & & \\
\hline \multirow{3}{*}{4} & \multirow{3}{*}{100} & \multirow{3}{*}{2} & 1 & 10 & 8 & \multirow{3}{*}{7} & \multirow{3}{*}{70} & \multirow{3}{*}{5,52} \\
\hline & & & 2 & 10 & 6 & & & \\
\hline & & & 3 & 10 & 6 & & & \\
\hline \multirow{3}{*}{5} & \multirow{3}{*}{1000} & \multirow{3}{*}{3} & 1 & 10 & 10 & \multirow{3}{*}{9} & \multirow{3}{*}{90} & \multirow{3}{*}{6,28} \\
\hline & & & 2 & 10 & 10 & & & \\
\hline & & & 3 & 10 & 9 & & & \\
\hline
\end{tabular}

Tabel 3 hasil penelitian uji toksisitas rumput laut $E$. cottonii didapatkan pada konsentrasi 1 ppm dengan jumlah larva 10 individu memliki persentase kematian $20 \%$, konsentrasi $10 \mathrm{ppm}$ persentase kematian $40 \%$, Konsentrasi 100 ppm persentase kematian $70 \%$ dan konsentrasi 1000 ppm persentase kematian $90 \%$. Berdasarkan data tersebut dapat disimpulkan bahwa tingkat toksisitas rumput laut meningkat sejalan dengan tingginya konsentrasi ekstrak rumput laut $E$. cottonii.

Untuk menentukan nilai $\mathrm{LC}_{50}$ didapatkan dengan memasukkan angka probit $(50 \%$ kematian larva uji).
Selanjutnya dibuat persamaan garis $y=a x+b$, dimana $y$ adalah konsentrasi larutan, dan $x$ adalah persen kematian larva. $\mathrm{LC}_{50}$ merupakan nilai $y$ yang diperoleh dengan memasukkan nilai $x=50 \%$.

Persamaan regresi dari ekstrak rumput laut $E$. cottonii yaitu y $=1,4379 x+$ 2,4165 . Nilai x merupakan nilai $\mathrm{LC}_{50}$ dan y bernilai 5, sehingga didapatkan nilai $\mathrm{LC}_{50}$ ekstrak E. cottonii yang dapat mematikan $50 \%$ hewan uji berdasarkan analisis probit sebesar 62,62 ppm (Gambar 1). Pernyataan di atas menunjukkan bahwa ekstrak $E$. cottonii besifat toksik terhadap A. salina, karena memiliki nilai $\mathrm{LC}_{50} \leq 1000$ ppm, 
suatu ekstrak menunjukkan aktivitas ketoksikan dalam BSLT jika ekstrak dapat menyebabkan kematian 50\% hewan uji pada konsentrasi kurang dari 1000 ppm
[11]. Penelitian [12] juga menyatakan bahwa suatu ekstrak dikatakan toksik apabila mempunyai nilai $\mathrm{LC}_{50} \leq 1000 \mathrm{ppm}$.

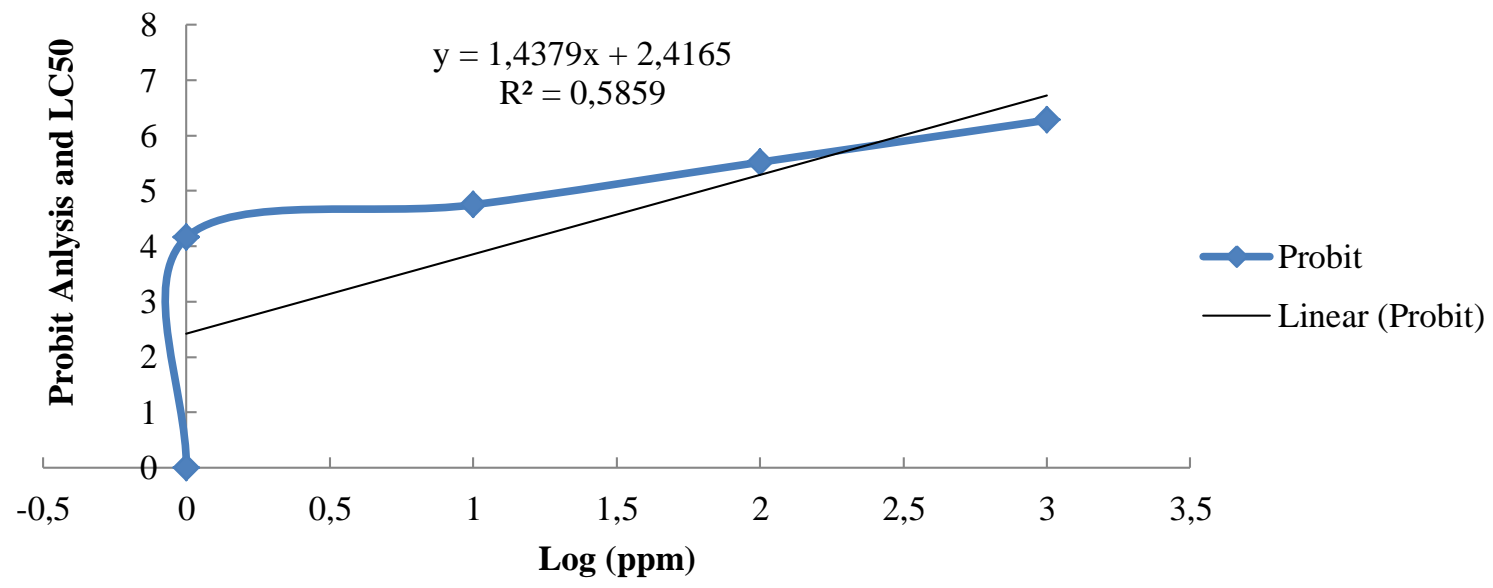

Gambar 1. Grafik Analisis Regresi Ekstrak E. Cottonii

Sehingga didapat nilai: $a=1,4379 ; \quad x=2,5836 / 1,4379$

$\mathrm{b}=2,4165$

Maka, $y=a x+b$

$$
\begin{aligned}
& 5=1,4379 x+2,4165 \\
& 5-2,4165=1,4379 x
\end{aligned}
$$

$$
\mathrm{x}=1,7966864
$$

$\mathrm{x}=\mathrm{LC}_{50}=\operatorname{antilog}(\mathrm{x})=62,62 \mathrm{ppm}$

Hasil uji toksisitas rumput laut

\begin{tabular}{|c|c|c|c|c|c|c|c|c|}
\hline $\begin{array}{l}\mathrm{N} \\
\mathrm{O}\end{array}$ & $\begin{array}{c}\text { Konsentrasi } \\
(\mathrm{ppm})\end{array}$ & $\begin{array}{c}\text { Log } 10 \\
\text { Konsentrasi }\end{array}$ & Ulangan & $\begin{array}{c}\text { Total } \\
\text { Larva (ind) }\end{array}$ & $\begin{array}{c}\text { Larva } \\
\text { Mati (ind) }\end{array}$ & $\begin{array}{l}\text { Mortalitas } \\
\text { (ind) }\end{array}$ & $\begin{array}{c}(\%) \\
\text { Kematian }\end{array}$ & Probit \\
\hline \multirow{3}{*}{1} & & & 1 & 10 & 0 & & & \\
\hline & 0 (kontrol) & - & 2 & 10 & 0 & 0 & - & - \\
\hline & & & 3 & 10 & 0 & & & \\
\hline \multirow{3}{*}{2} & & & 1 & 10 & 1 & & & \\
\hline & 1 & 0 & 2 & 10 & 2 & 1 & 10 & 4,72 \\
\hline & & & 3 & 10 & 1 & & & \\
\hline \multirow{3}{*}{3} & & & 1 & 10 & 3 & & & \\
\hline & 10 & 1 & 2 & 10 & 4 & 4 & 40 & 4,75 \\
\hline & & & 3 & 10 & 4 & & & \\
\hline \multirow{3}{*}{4} & & & 1 & 10 & 4 & & & \\
\hline & 100 & 2 & 2 & 10 & 7 & 5 & 50 & 5,00 \\
\hline & & & 3 & 10 & 5 & & & \\
\hline \multirow{3}{*}{5} & & & 1 & 10 & 10 & & & \\
\hline & 1000 & 3 & 2 & 10 & 8 & 9 & 90 & 6,28 \\
\hline & & & 3 & 10 & 9 & & & \\
\hline
\end{tabular}
Gracillaria sp dapat dilihat pada Tabel 4.

Tabel 4. Hasil Uji Toksisitas Ekstrak Rumput Laut Gracillaria sp

Hasil uji toksisitas rumput laut Gracillaria. sp pada konsentrasi 1 ppm dengan larva 10 individu memiliki persentase kematian $10 \%$, konsentrasi 10 ppm persentase kematian $40 \%$, konsentrasi 100 ppm persentase kematian 50\%, konsentrasi 1000 ppm persentase kematian
90\%. Pada data hasil uji toksisitas dapat disimpulkan bahwa tingkat toksisitas meningkat sejalan dengan tingginya konsentrasi ekstrak rumput laut Gracillaria $\mathrm{sp}$.

Berdasarkan Tabel 4 hasil penelitian uji toksisitas rumput laut Gracillaria sp di 
atas, untuk menentukan nilai $\mathrm{LC}_{50}$ didapatkan dengan memasukkan angka probit (50\% kematian larva uji). Selanjutnya dibuat persamaan garis $y=a x$ $+b$, dimana $y$ adalah konsentrasi larutan, dan $x$ adalah persen kematian larva. $\mathrm{LC}_{50}$ merupakan nilai $y$ yang diperoleh dengan memasukkan nilai $x=50 \%$. Dari tabel 5 , untuk mencari nilai $\mathrm{a}, \mathrm{b}$ dan $\mathrm{r}$ didapat dengan: $\mathrm{X}=\log \mathrm{ppm} ; \mathrm{Y}=$ Probit).

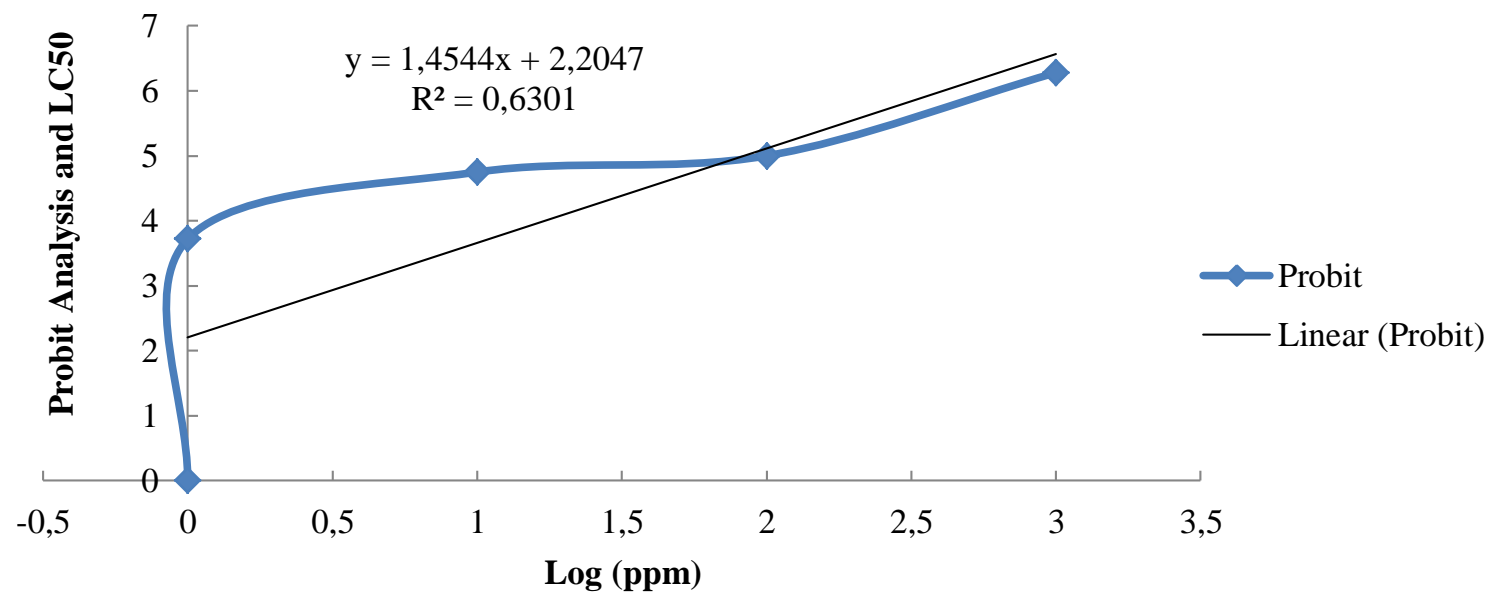

Gambar 2. Grafik Analisis Regresi terhadap Konsentrasi Ekstrak Gracillaria sp.

Sehingga didapat nilai $: \mathrm{a}=1,4544 ; \mathrm{b}=$ 2,2047

$$
\begin{aligned}
& \text { Maka, } \mathrm{y}=\mathrm{ax}+\mathrm{b} \\
& \begin{aligned}
5=1,4544 \mathrm{x}+2,2047 \\
5-2,2047=1,4544 \mathrm{x} \\
\mathrm{x}=2,7953 / 1,4544 \\
\mathrm{x}=1,9219414
\end{aligned}
\end{aligned}
$$$$
\mathrm{x}=\mathrm{LC}_{50}=\operatorname{antilog}(\mathrm{x})=83,55 \mathrm{ppm}
$$

Persamaan regresi dari ekstrak Gracillaria sp yaitu y $=1,4544 \mathrm{x}+2,2047$. Nilai x merupakan nilai $\mathrm{LC}_{50}$ dan y bernilai 50. Sehingga didapatkan nilai $\mathrm{LC}_{50}$ ekstrak Gracillaria sp yang dapat mematikan 50\% hewan uji berdasarkan analisis probit sebesar 83,55 ppm. Pernyataan di atas menunjukkan bahwa ekstrak Gracillaria sp juga besifat toksik terhadap A. salina, karena memiliki nilai $\mathrm{LC}_{50} \leq 1000$ ppm. [13] menyatakan senyawa yang toksik terhadap A. salina juga toksik terhadap sel kanker, hal ini membuktikan bahwa pengujian ini merupakan tahapan awal untuk mengetahui apakah suatu senyawa bersifat toksik atau tidak terhadap A. salina. Hal serupa juga berlaku terhadap Gracillaria sp, dimana adanya pengaruh penambahan ekstrak terhadap nilai $\mathrm{LC}_{50}$ dari uji toksisitas ekstrak n-heksana rumput laut Gracillaria sp. terhadap larva A. salina Leach, yang dibuktikan dengan semakin besar konsentrasi yang digunakan maka semakin besar persentase kematian A.salina.

Hasil penelitian uji toksisitas dari kedua spesies rumput laut tersebut diketahui bahwa tingkat toksisitas ekstrak rumput laut E. cottonii dan Gracillaria sp sama-sama meningkat sejalan dengan meningkatnya konsentrasi ekstrak, sejalan dengan penelitian yang telah dilakukan oleh [14] menyatakan semakin besar konsentrasi yang digunakan maka semakin besar persentase kematian A. salina. Tingkat toksisitas dari kedua jenis rumput laut memiliki kandungan senyawa aktif yang berbeda dan memiliki bioaktivitas terhadap larva udang A. salina. Sehingga dapat dilakukan pengujian bioaktivitas lebih lanjut mengenai potensinya sebagai senyawa obat.

\section{Konsentrasi Aman (Safe Concentration)}

Berdasarkan hasil uji toksisitas ekstrak rumput laut $E$. cottonii dan Gracillaria sp, nilai konsentrasi aman bagi 
kelangsungan hidup $A$. salina didapatkan sebesar 6,262 ppm untuk E. cottonii dan 8,355 ppm untuk Gracillaria sp. Nilai konsentrasi aman di atas didapatkan dari perhitungan $10 \%$ nliai $\mathrm{LC}_{50}$ masing-masing ektrak uji. [8] menyatakan bahwa nilai yang aman (safe concentration) bagi organisme dari daya racun toksisitas adalah $10 \%$ dari nilai $\mathrm{LC}_{50}$.

Nilai konsentrasi aman ini berada di bawah nilai $\mathrm{LC}_{50}$, sesuai dengan penelitian [15] yang menyatakan bahwa untuk mendapatkan konsentrasi yang aman penggunaannya terhadap hewan uji konsentrasi dibuat dibawah nilai $\mathrm{LC}_{50}$ nya. Konsentrasi aman (safe concentration) merupakan konsentrasi maksimum bahan toksik yang tidak membahayakan organisme setelah bersentuhan dengan bahan uji dalam periode waktu lama, setidak-tidaknya satu generasi [16].

Kelangsungan hidup merupakan nilai persentasi dari organisme yang hidup pada akhir pengujian dari jumlah keseluruhan yang diuji pada awal pengujian. Pada penelitian ini kelangsungan hidup sangat dipengaruhi oleh kualitas air. Salah satu cara menciptakan lingkungan yang ideal adalah dengan melakukan penggantian air. Selama penelitian ini berlangsung, penyiponan, penggantian air dan pemberian aerasi pada media uji selalu dilakukan dan dikontrol, sehingga kualitas air dalam media uji dengan perlakuan maupun kontrol bisa dikatakan baik.

Kelangsungan hidup A. salina yang tinggi terdapat pada kontrol, hal ini diduga karena kualitas air kontrol yang diberikan baik, serta A. salina mampu mentoleransi kondisi lingkungan seperti kualitas air selama penelitian ini ada dalam kisaran layak bagi kelansungan hidup A. salina Oleh sebab itu, untuk menjamin kelangsungan hidup $A$. salina maka konsentrasi yang diperbolehkan tidak lebih dari 6,262 ppm untuk E. cottonii dan 8,355 ppm untuk Gracillaria sp.Berdasarkan uji toksisitas ekstrak rumput laut E. cottonii dan Gracillaria sp, nilai konsentrasi aman (safe concentration) bagi organisme dari daya racun toksisitas adalah $10 \%$ dari nilai $\mathrm{LC}_{50}$. Hal ini menunjukkan bahwa konsentrasi yang aman bagi kelangsungan hidup A. salina yaitu sebesar $6,262 \mathrm{ppm}$ untuk E. cottonii dan 8,355 ppm untuk Gracillaria sp. Oleh sebab itu, untuk menjamin kelangsungan hidup A. salina maka konsentrasi yang diperbolehkan tidak lebih dari 6,262 ppm untuk E. cottonii dan 8,355 ppm untuk Gracillaria sp.

\section{KESIMPULAN DAN SARAN Kesimpulan}

Nilai $\mathrm{LC}_{50}$ ekstrak rumput laut $E$. cottonii dan Gracillaria sp menggunakan n-heksan terhadap larva A. salina masingmasing adalah 62,62 ppm dan 83,55 ppm. Konsentrasi yang aman ekstrak E. cottonii dan Gracillaria sp terhadap A. salina masing-masing adalah $6,262 \mathrm{ppm}$ dan $8,355 \mathrm{ppm}$.

\section{Saran}

Perlu dilakukan penelitian lanjutan mengenai kandungan serta potensi senyawa bioaktif yang terkandung dalam ekstrak rumput laut E. cottonii dan Gracillaria sp, sehingga dapat dilakukan pengujian bioaktivitas lebih lanjut mengenai potensinya sebagai senyawa obat.

\section{DAFTAR PUSTAKA}

1. Khurniasari, D.W. (2004). Potensi Antikanker Senyawa Bioaktif Ekstrak Kloroform dan Metanol Makroalgae Sargassum duplicatum J. Agardh. Fakultas Biologi Universitas Gadjah Mada Jogjakarta. Jogjakarta

2. Krishnaraju, A. V., T. V Rao., D. Sundararaju., M. Vanisree., H-S. Tsay., and G. V. Subbaraju. (2006). Assessment of Bioactivity of Indian Medicinal Plants Using Brine 
Shrimp (Artemia salina) Lethality Assay. International Journal of Applied Science and Engineering, 3: 125 - 135.

3. Colegate, S.M. and R.J. Molyneux. (2007). Bioactive Natural Products: Determination, Isolation and Structural Determination Second Edition. Prancis: CRC Press.

4. Hiola, R., R. Tuiyo dan Syamsuddin. (2014). Pengaruh Salinitas yang Berbeda terhadap Penetasan Kista Artemia sp. di Balai Benih Ikan Kota Gorontalo Provinsi Gorontalo. Jurnal Ilmiah Perikanan dan Kelautan, 2 : 52 - 55.

5. Harmita dan M. Radji. (2008). Analisis Hayati. Penerbit Buku Kedokteran. Jakarta.

6. Tyas. (2016). Uji Toksisitas Letal $\mathrm{Cr}^{6+}$ terhadap Ikan Nila (Oreochromis niloticus). Fakultas Perikanan dan Ilmu Kelautan. Jurnal Ilmu Pertanian Indonesia, 2: 128 - 132.

7. Sangi, M., L. Momuat, dan M. Kumaunang. (2012). Uji Toksisitas dan Skrining Fitokimia Tepung Gabah Pelepah Aren (arenga pinnata). Jurnal Ilmiah Sains, 12: 128134.

8. Nedi, S., Thamrin., dan H. Marnis. (2006). Toksisitas Deterjen terhadap Benih Ikan Kakap Putih (Lates calcarifer, Bloch). Berkala Perikanan Terubuk, 33: 75 - 81.

9. Meyer, B.N., N.R. Ferrigni, J.E. Putnan, L.B. Jacobsen, D.E. Nicholas, and J.L. Mclaughlin. (1982). Brine Shrimp: A Conveinient General Bioassay For Active Plant Constituents, Planta Medica. 4 : 31 - 34.

10. Nur, A. dan Y. Zuhud. (2011). Kanker Lenyap Berkat Sirsak. Jakarta: PT. Agro Media Pustaka.

11. Sharo. M. N., Ningsih, Rachmawati., A. Nasichuddin, Ahmad, dan Hanapi. (2013). Uji Toksisitas dan Identifikasi Senyawa Ekstrak Alga Merah (Eucheuma cottonii) Terhadap Larva Udang Artemia salina Leach. Jurnal Alchemy, 3: 170 - 177.

12. Sukardiman., R. Abdul dan P. N. Fatma. (2004). Uji Praskrining Aktivitas Antikanker Ekstrak Eter dan Ekstrak Metanol Marchantia planiloba Steph. dengan Metode Uji Kematian Larva Udang dan Profil Densitometri Ekstrak Aktif. Majalah Farmasi Airlangga, 4: 97 - 100.

13. Astuti, P., S. Utami, T. Pratiwi, T. Hertiani, G. Alam, A. Tahir and S. Wahyono. (2005). Antimicrobial Activity Screening of Marine Sponges Extracts Colected from Barang Lomposea. Journal of Traditional Medicine, 10:32.

14. Hardiko, F. (2018). Toksisitas Ekstrak Rumput Laut (Eucheuma cottonii) dengan Pelarut n-Heksana dan Etil Asetat terhadap Artemia salina. Fakultas Perikanan dan Kelautan Universitas Riau.

15. Suryati, E. (2015). Uji Ekstrak Ramuan "Kandungan Subur" (Kunyit (Curcuma domestica Val.), Kencur (Kaempferia galanga L.), Adas (Foeniculum vulgare Mill.) dan Pegagan (Centella asiatica)) pada Berbagai Pelarut terhadap Toksisitas Larva A. salina. Fakultas Sains dan Teknologi Universitas Islam Negri Maulana Malik Ibrahim, Malang.

16. Kunsah, B. dan R. Widyastuti. (2018). Uji Toksisitas Akut Kulit Kentang (Solonum tuberosum L.) terhadap Larva A. salina Leach dengan Metode BSLT (Brine Shrimp Lethality Test). Prodi D3 Analisis Kesehatan Universitas Muhammadiyah, Surabaya. 